Check for updates

1 St George's University of London

2 University College, London

3 Imperial College London

Twitter: @mohammadrazai, @ldndoc, @RaoMala, @Azeem_Majeed Cite this as: BMJ 2022;376:0424 http://dx.doi.org/10.1136/bmj.0424 Published: 17 February 2022

\section{Now is the time for radical action on racial health inequalities}

\section{A new report by the NHS Race and Health Observatory makes robust recommendations-we must act on them, write Mohammad S Razai and colleagues}

\author{
Mohammad S Razai, ${ }^{1}$ Doug McKechnie, ${ }^{2}$ Mala Rao, ${ }^{3}$ Azeem Majeed ${ }^{3}$
}

The magnitude of racial health inequalities reported in the NHS Race and Health Observatory's recent review comes as no surprise. ${ }^{1}$ It highlighted the overwhelming, stark, widespread, and longstanding inequalities that people from ethnic minorities in the UK experience in access to healthcare and outcomes. The report found that this occurs "at every stage, throughout the life course, from birth to death" and is "rooted in experiences of structural, institutional, and interpersonal racism." ${ }^{1}$ This evidence has been known for a long time, with the disproportionate impacts of covid-19 on people from ethnic minorities drawing even greater attention to and wider recognition of these facts. ${ }^{23}$ Will evidence, however, be enough to compel those charged with the nation's health to acknowledge and take urgent action to redress these egregious inequalities?

Firstly, there are significant gaps in the literature, as well as poor quality, inconsistent, and incomplete data in some places. Secondly, the review only focused on five "priority" areas: mental health, maternal and neonatal care, digital healthcare, genomic medicine, and the NHS workforce. However, the evidence that exists, which spans over a decade and has been examined by this independent body, should be a wake-up call for the government and the NHS.

Fear and distrust run through most of this review, particularly in mental healthcare, maternal care, and digital access. Furthermore, negative experiences, poor communication, and substandard care marked by insensitive, discriminatory interactions are also common among ethnic minorities, who are then deterred from seeking care from the NHS. There are significant barriers to accessing psychological therapies, including cognitive behavioural therapies and children's mental health services, due to fewer referrals from general practice, but also lower levels of health literacy, poorer access to online health services, and resultant challenges to self-referral. This illustrates the need for a broader approach to tackle health inequalities, including working on areas such as education and poverty.

People from ethnic minority groups, particularly Black individuals, are more likely to face compulsory admission to psychiatric wards, receive harsher treatments, and are more likely to be restrained and put into seclusion. ${ }^{14} \mathrm{NHS}$ staff from ethnic minorities do not fare any better than the patients. Their experiences are marked by racist abuse-both from patients and other staff-lack of career progression, and an ethnic pay gap. ${ }^{15}$

The review suggests robust recommendations on how to bring about a radical and imaginative change in policy, practice, attitude, and approach. It starts with better, more accurate, and granular ethnic data monitoring in the NHS and linking these clinical data across the health service to improve clinical outcomes for ethnic minority groups. It is also necessary to improve access to and experiences of care by more targeted investment, as well as providing resources for some areas, such as high quality interpreter services. ${ }^{1}$

There is also much that needs to be done to build trust. The impact of the covid-19 pandemic, especially the lower uptake of covid-19 vaccines among certain groups, has brought the issue of trust into sharp relief. ${ }^{6}$ Trust cannot be built if the government continues to abnegate responsibility and turn its face away from the lived experiences of racism, in particular systemic racism, among ethnic minorities. A sincere attempt to understand and engage with communities will do much to establish trust, which will, in turn, lead to better health outcomes.

Neither evidence nor a clarion call for action alone-no matter how clarifying and stark-would lead to meaningful change. We have been here before. Numerous past inquiries, by governments and independent bodies alike, have made urgent calls for a new approach, only to be frustrated by inaction, endless deferrals, and delays. ${ }^{3}$

A strong political will is, therefore, required to turn the wheels of change. Inaction costs lives and would lead to a worsening of systematic socioeconomic and health inequalities. For those of us who have raised the ineluctable facts of racism-in particular systemic racism-as a major driver of racial health inequalities, ${ }^{7}$ our position is perhaps encapsulated by the author and public intellectual CS Lewis in his 1942 novel, The Screwtape Letters.

"The greatest evil is done not in sordid dens of evil ordered (moved, seconded, carried, and minuted) in clear, carpeted, warmed, and well-lighted offices, by quiet men with white collars and cut fingernails and smooth-shaven cheeks who do not need to raise their voices." 8

The time to tackle unconscionable racial health inequalities in this country is now and the NHS Race and Health Observatory's review can help start that change.

Competing interests: None declared.

Provenance and peer review: Commissioned; not peer reviewed.

The views expressed are those of the authors and not necessarily those of the NHS, the NIHR, or the Department of Health and Social Care. that Dickens loved to paint, but it is conceived and 


\section{OPINION}

1 Ethnic inequalities in healthcare: a rapid evidence review. NHS Race and Health Observatory. February 2022. www.nhsrho.org/wp-content/uploads/2022/02/RHO-Rapid-Review-Final-Report_v.7.pdf.

2 Racism in medicine. The BMJ. 2020. https://www.bmj.com/racism-in-medicine

3 Razai MS, Kankam HKN, Majeed A, Esmail A, Williams DR. Mitigating ethnic disparities in covid-19 and beyond. BM/2021;372:m4921. doi: 10.1136/bmj.m4921. pmid: 33446485

4 Gnanapragasam SN, Menon KV. Improving the mental health of South Asian Populations in the United Kingdom. https://www.emfoundation.org.uk/wp-content/uploads/2021/12//mprovingMental-Health-Of-South-Asian-Populations-in-the-UK-Report-Dec-2021-1.pdf

5 England NHS. Medical Workforce Race Equality Standard (MWRES) WRES indicators for the medical workforce 2020. July 2021. https://www.england.nhs.uk/wp-content/uploads/2021/07/MWRES-DIGITAL-2020_FINAL.pdf

6 Razai MS, Osama T, McKechnie DGJ, Majeed A. Covid-19 vaccine hesitancy among ethnic minority groups. BMJ 2021;372:n513. doi: 10.1136/bmj.n513. pmid: 33637577

7 Gopal DP, Rao M. Playing hide and seek with structural racism. BMJ2021;373:n988. doi: 10.1136/bmj.n988. pmid: 33883165

$8 \quad$ Lewis CS. Selected Books - Screwtape Letters. Harper Collins Religious, 1999: 736. 